\title{
Selective collection and waste-to-energy strategies: which interaction?
}

\author{
E. C. Rada \\ University of Trento, Italy
}

\begin{abstract}
This paper updates and analyses the interaction between the selective collection of municipal solid waste and waste-to-energy strategies in a case-study where high efficiencies of source separation have been reached thanks to more than a decade of efforts. For a better understanding of the local waste management history, in the selected case-study (province of Trento, Italy) the most important years were analyzed and characterized. In the selected case-study, particular attention has been given to the organization of selective collection and environmental protection, the location being also a tourist area. The variability of selective collection (that increased its efficiency year by year) affects the characteristics of the residual municipal solid waste and subsequently its "lower heating value" and the waste-to-energy strategies. The residual municipal solid waste generated today is similar to a solid recovered fuel. Its exploitation in existing industrial plants for energy recovery represents one of the present-future strategies to be developed. Keywords: MSW, RMSW, selective collection, SRF, waste-to-energy.
\end{abstract}

\section{Introduction}

In recent years, municipal solid waste (MSW) has become one of the most important indicators of the socio-economic development of a country [1]. The present paper updates and analyses the interaction between the selective collection of MSW and waste-to-energy in an area in the north part of Italy [2].

Italy is one of the co-founding countries of the European Community, which reached a 35\% efficiency of selective collection (SC) at national level in 2013 [3]. It is clear that duration of membership is not correlated with the SC organization that depends on different visions and priorities of waste management (France and Belgium, co-founding countries, have SC under $40 \%$; Slovenia, instead after only 
7 years arrived to $45 \%$ ). However, among the 28 countries, only 3 northern countries exceeded $50 \%$ of the SC target at national level (Germany, Luxembourg, Netherlands, Sweden) and in the others, the SC has very variable efficiency (1-45\%) [4].

The first concept of waste selective collection (kerbside) and open dumps constructed at about $2 \mathrm{~km}$ away from the villages, date back to the birth of the first civilization in 2000 B.C. [5]. After the war and with the economic-industrial development and consequent pollution, some environmental limits and indications regarding waste collection, treatment and landfilling (422/75/EC, 94/62/EC) were developed and implemented.

The first proposed treatment for the selected organic waste was the composting one [6], followed by anaerobic digestion [7]. After few experiences around the world, in the $60 \mathrm{~s}$ the incineration was massively proposed in order to treat the various kinds waste [8]. Since 2000, the mechanical biological treatments (MBT) were widely implemented for MSW [9, 10]. In recent years the MSW sector paid more and more attention to the energy optimization and environmental impact minimization of the above-mentioned processes [11-14].

Recently, SC increased its role in many countries for many fractions [15-19] as an integrated option of the conventional processes, showing an important impact on the management of the residual MSW (RMSW). The variability of SC affects the characteristics of the RMSW and subsequently its lower heating value (LHV) and the waste-to-energy strategies. The RMSW in the areas where SC has high efficiency could be considered as solid recovered fuel (SRF) [20].

In this context, the aim of this paper is to analyze the consequences of the evolution of the MSW selective collection towards the strategies of waste-toenergy, referring to an Italian case-study, where particular attention has been given to the organization of SC and environmental protection starting from 2000.

\section{Materials and methods}

The Trentino region was selected as case-study in order to give an overview of the waste SC development over the years and the consequences of its implementation on waste-to-energy strategies. In 2013, in the selected casestudy, the inhabitants were about 610,000 (15\% were assumed as inhabitants equivalent thanks to the tourism influence) and produced about $265 \mathrm{kton}$ of MSW [21]. The territory involved is characterized by a significant richness of data in the MSW sector. This is the consequence of a political choice that allowed opening a specialized agency for "observing" the waste sector in order to maximize mass valorization before facing the implementation of a waste-to-energy plant.

The first step in order to improve the MSW management in the chosen province was made through the regulation L.P. 29/82 that forbade the open dumps (300 in province in 1982) and imposed the sanitary landfills (7 controlled landfills were realized in the following years). However, the MSW collection and transportation to a final disposal was given to the municipalities since 1941, thanks to the legislation 366/1941.

In 1993, the first disposal plan for MSW was developed (SC efficiency at the 
beginning was near 4\%), followed by updates: 1997, 2002 and 2006. In the following years, a continuous update of data on waste was performed (SC efficiency reached $75 \%$ in 2013 ).

In the year 1998, the same province issued the L.P. n. 5/1998 regulation in order to give information about the organization and the development of SC and about how to minimize the MSW landfilling.

The consequences can be seen in the data reported in the waste management plans issued in the last two decades: data from the years 1994, 2001, 2004, 2010 and 2012 were analyzed in order to extract the information needed for characterizing the local dynamics of the MSW sector. At the beginning almost all the collected waste was going to landfills with and without biogas recovery and only a very small part of the biodegradable waste was used for compost production. The situation changed significantly thanks to the German Topfer Decree in 1991 that enforced the concept of the material recovery facilities (MRF). As a consequence, in the chosen province, the MSW collection was made through three bins: biodegradable, recyclable and residual waste.

In fig. 1, the composition of MSW is shown pointing out the present situation (first bars) and comparing it to that of the previous years.

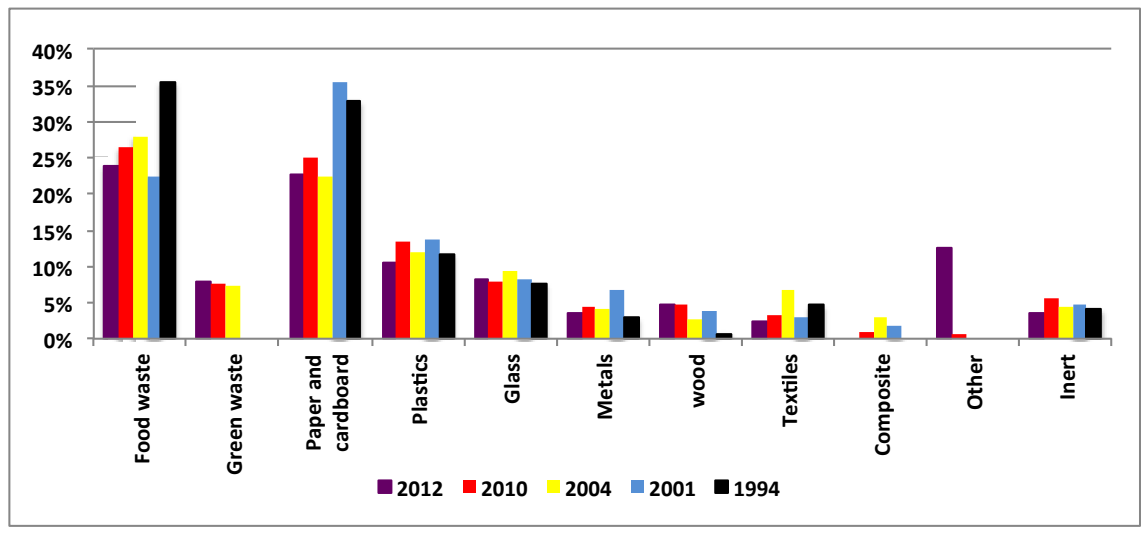

Figure 1: MSW composition during the last two decades.

In 2001 and 1994 green waste was not classified; this is the reason why the 1994 bar for food waste is the highest. The scenario in 2001 was similar in terms of MSW composition but the enforcement of the Italian Ronchi's Decree $(22 / 1997)$ accelerated the evolution of SC, also including the food waste collection. The SC was performed through home collection (kerbside), street collection and eco-stations, for specific fractions or mixed fractions [17, 20]. This system is used also today. In table 1, an overall view of the SC system in 2001 is reported for the 11 municipalities of the chosen province. In some municipalities, multimaterials (glass, plastic, can) are collected together, in others one by one. The RMSW were sent to 8 landfills and in two of them, the RMSW was added as bale. 
Table 1: SC collections strategies.

\begin{tabular}{|c|c|c|c|c|c|c|c|c|c|c|c|c|c|}
\hline & 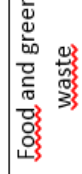 & 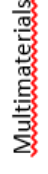 & $\begin{array}{l}\tilde{0} \\
\frac{\pi}{0}\end{array}$ & 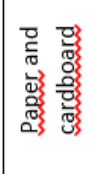 & $\begin{array}{l}\text { 苛 } \\
\frac{\pi}{\alpha}\end{array}$ & 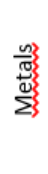 & 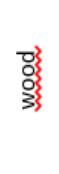 & 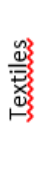 & 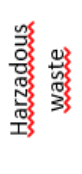 & 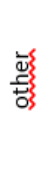 & 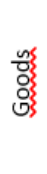 & 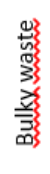 & $\sum_{\infty}^{3}$ \\
\hline 1 & & & & & & & & & & & & & \\
\hline 2 & & & & & & & & & & & & & \\
\hline 3 & & & & & & & & & & & & & \\
\hline 4 & & & & & & & & & & & & & \\
\hline 5 & & & & & & & & & & & & & \\
\hline 6 & & & & & & & & & & & & & \\
\hline 7 & & & & & & & & & & & & & \\
\hline 8 & & & & & & & & & & & & & \\
\hline 9 & & & & & & & & & & & & & \\
\hline 10 & & & & & & & & & & & & & \\
\hline 11 & & & & & & & & & & & & & \\
\hline & $\begin{array}{l}\text { Street } \\
\text { bell }\end{array}$ & $\begin{array}{r}\text { Str } \\
\text { cont }\end{array}$ & & treet bin & & & $\begin{array}{c}\text { Eco- } \\
\text { station }\end{array}$ & & CRZ & rbsit & & & there \\
\hline
\end{tabular}

In 2004 the construction of a centralized incinerator for the valorization of the residual MSW (RMSW) was under discussion (its project was analyzed and modified over the next decade). The SC of materials with high biodegradability and moisture content increased reaching about half of the available steams.

In 2010, the incinerator construction was still delayed. In the meanwhile, the management of the growing streams of food and green waste selectively collected was associated to the planning of 4 anaerobic digesters (one of them started its activity in 2012; a second one was completed, but its full operation was delayed because of the need of an optimization of the recirculation streams) mostly coupled with post-composting after biogas exploitation. The obtained results in diverting biodegradable materials from landfilling are in agreement with the targets of the EU landfilling directive.

A new regulation for the solid recovered fuel (SRF) from MSW was implemented in Italy in 2010 [20, 22, 23]. It reopened, in 2012, the discussion on the use of RMSW as a SRF-like in co-combustion plants already existing also out of the province.

In 2013, it was decided to exclude the incinerator from the waste management plan. A second digester available was operated partially, but a full performance is expected in 2014. From the economic point of view, the amount of RMSW to be treated is going to be too low for such a plant. The new vision includes bio-drying and post-treatment for SRF production as local option for RMSW management $[20,22,23]$. The SRF solution was proposed also in order to recover combustible materials from a landfill where about $10^{5}$ waste bales were stored.

In spite of a near steady composition of MSW, the variation of the RMSW characteristics as a result of SC dynamics has changed the strategies for its treatment. Useful parameters for analyzing this evolution are the lower heating 
value (LHV) of RMSW, the rate of exploitable energy from MSW (as RMSW) and the percentage of food waste in RMSW. All these parameters were assessed for the five years of reference.

\section{Results and discussion}

Fig. 2 shows data related to each of the considered years, concerning the dynamics of the RMSW composition. The decrease of food waste percentage as consequence of source separation is clear. A higher LHV of RMSW has to be expected. The implementation of the limits requested by the regulation 22/97 (15\% SC efficiency in $1999,25 \%$ in $2001,35 \%$ in 2003 , and for the following years, $40 \%$ in 2005 and $50 \%$ in 2007 respectively) changed significantly the composition of RMSW as can be seen from fig. 2 .

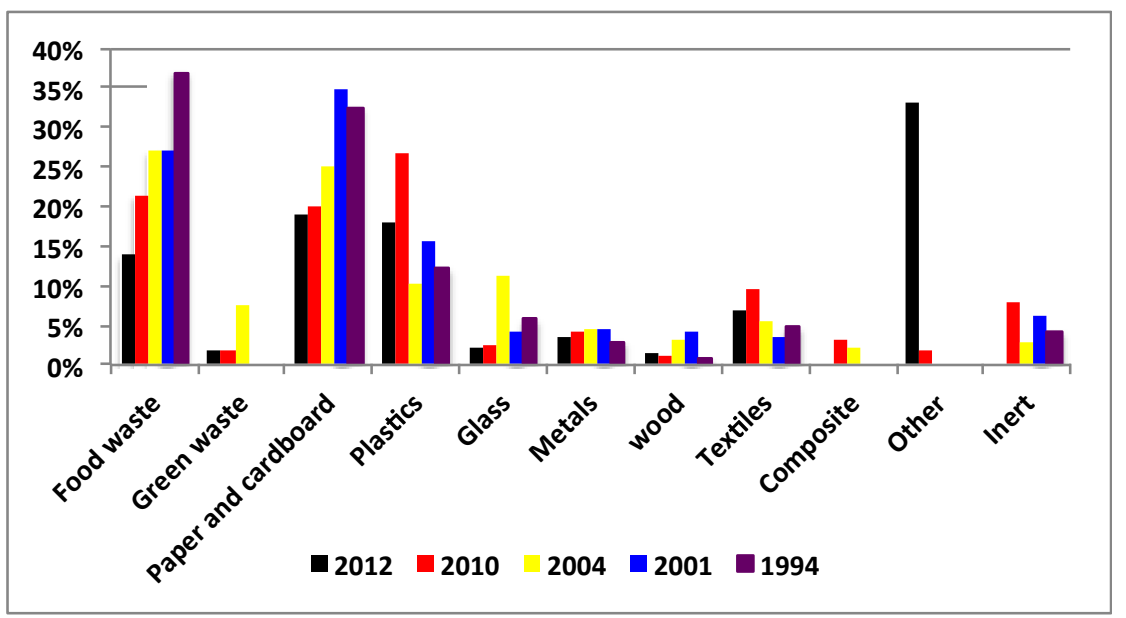

Figure 2: RMSW composition during the last two decades.

It must be noted that the percentage of the fraction "other" for 2012 is only apparently anomalous; indeed its high value depends on the different classification of some materials compared to the previous years; in particular, there is an emerging amount of diapers that in 2012 is classified only as "other". This is the reason why the fraction "composite" is zero in 2012.

Fig. 3 shows the trend of SC of the main streams. The evolution of the citizens' behavior is remarkable: for instance, about 20 years ago the rate of source separation for paper and cardboard was around 5\%; today it is higher than $75 \%$. Food waste segregation changed too: from zero to around $75 \%$. A target of $85 \%$ is expected for this last stream. Applying this value to a generation of $60,000 \mathrm{t} / \mathrm{y}$ and assuming a conversion rate of $0.080 \mathrm{Nm}^{3}$ of $\mathrm{CH}_{4}$ per $\mathrm{kg}$ of food waste fed in the planned digesters, the potential production of methane in the province is around 4 millions of cubic meters per year. An efficiency of electrical conversion as $40 \%$ could give a yearly generation of electricity around 16 million of $\mathrm{kWh}_{\mathrm{el}}$. 


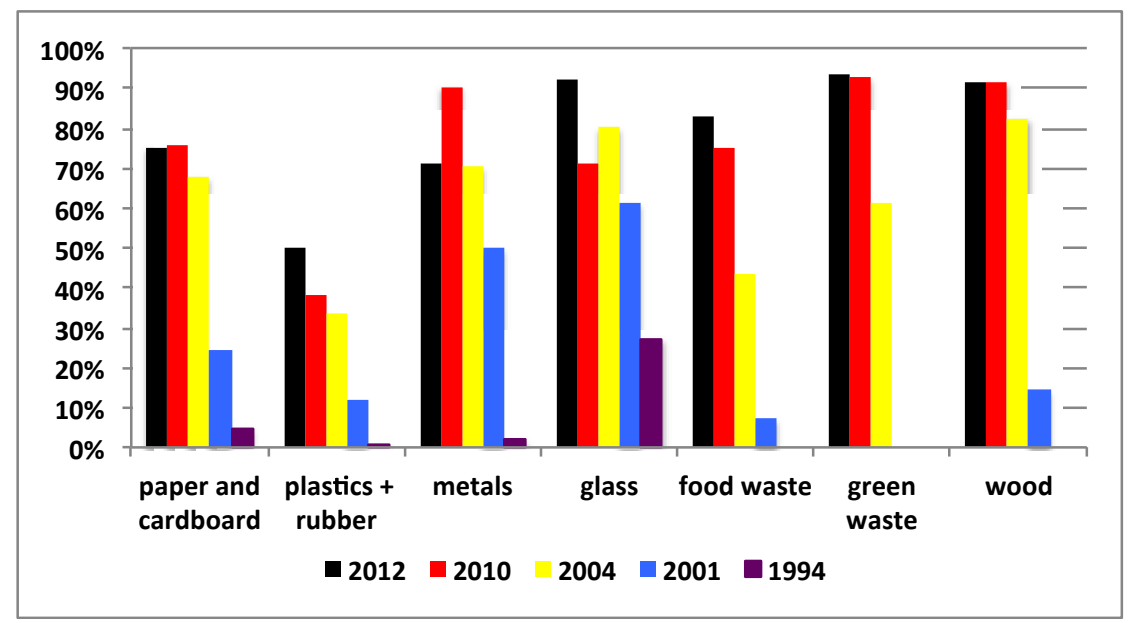

Figure 3: SC during the last two decades (percentage of interception).

The citizens' effort allowed reaching overall efficiencies as follows: about $4 \%$ in $1994,16 \%$ in $2001,32 \%$ in $2004,61 \%$ in $2010,67 \%$ in 2012 and $71 \%$ in 2013 respectively. After a slight delay in complying with the Ronchi's targets, a change of attitude can be observed after 2004: the efficiency doubled in only 6 years. One explanation can be related to the organizing efforts of the local authorities that set specific initiatives for decreasing the amount of RMSW to be sent to the proposed incineration. After 2010 additional percentage points were obtained thanks to refining actions.

In fig. 4, data on LHVs of MSW and RMW are reported for the five years. The present situation points out how SC has recently increased the LHV of RMSW compared to the one of MSW. Some comments can be made:

- The initial value of LHV (1994) was already adequate for direct combustion; this had to be expected as the studied area was classified as high income economy still in the 90 s;

- The "concentration" of energy in the RMSW of 2010 cannot be the unique parameter to be taken into account for analyzing the energy viability of the present scenario; indeed another aspect to be considered is the ratio between the energy available in 1 ton of MSW and the energy available in the respective amount of RMSW;

- It is a general opinion that SC causes an increase of LHV of RMSW; in reality, the available data demonstrate that this trend is approximately visible from 1994 to 2010 (apart from the fluctuation in 2004), but after that year, the extreme source separation of light packaging made the energy content of RMSW poorer;

- The LHV of MSW in 2012 is unexpectedly lower than the one in 2010; this can be partially explained by the higher percentage of "other" fraction, with consequent difficulty in assessing its LHV. 


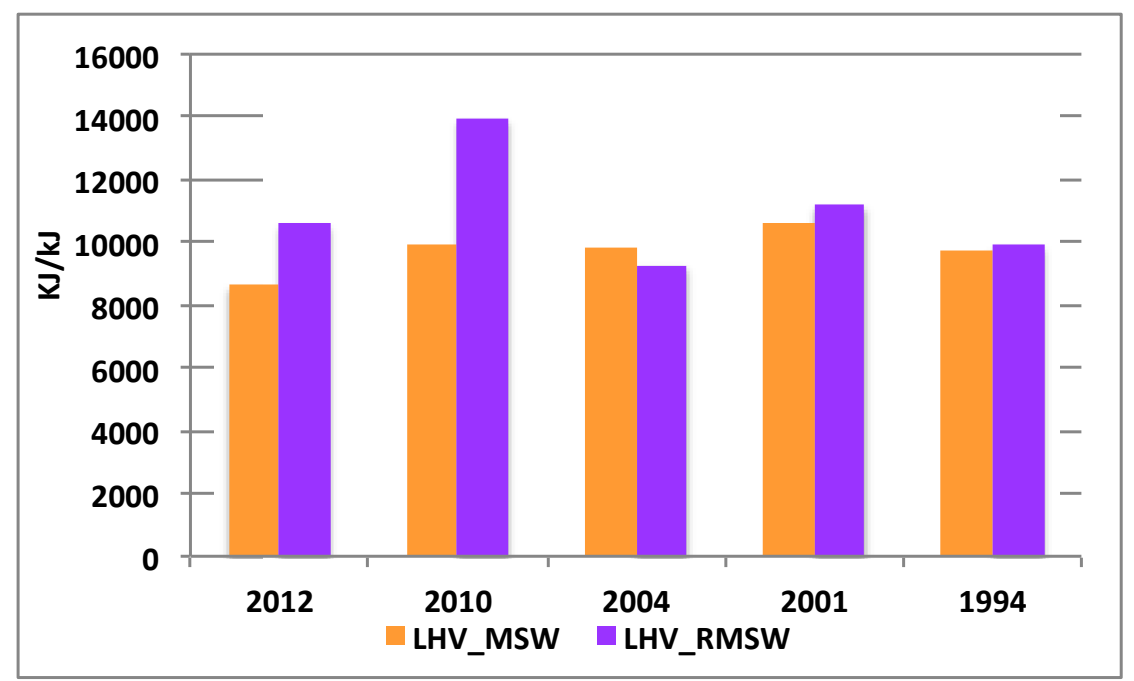

Figure 4: LHV of MSW and RMSW during the last two decades.

The energy ratio is presented in fig. 5 where it is clear that the higher SC is, the lower the energy exploitability rate, as a consequence of the segregation of waste fractions with a positive energy content (plastics, paper and cardboard in particular). Taking into account the MSW per capita amount of 2010 $\left(469 \mathrm{~kg} \mathrm{inh}^{-1} \mathrm{y}^{-1}\right)$, the SC rate $(65 \%)$, the population with tourists expressed as resident equivalents $(574,373)$ and the LHV of $\operatorname{RMSW}(13,939 \mathrm{~kJ} / \mathrm{kg})$, an

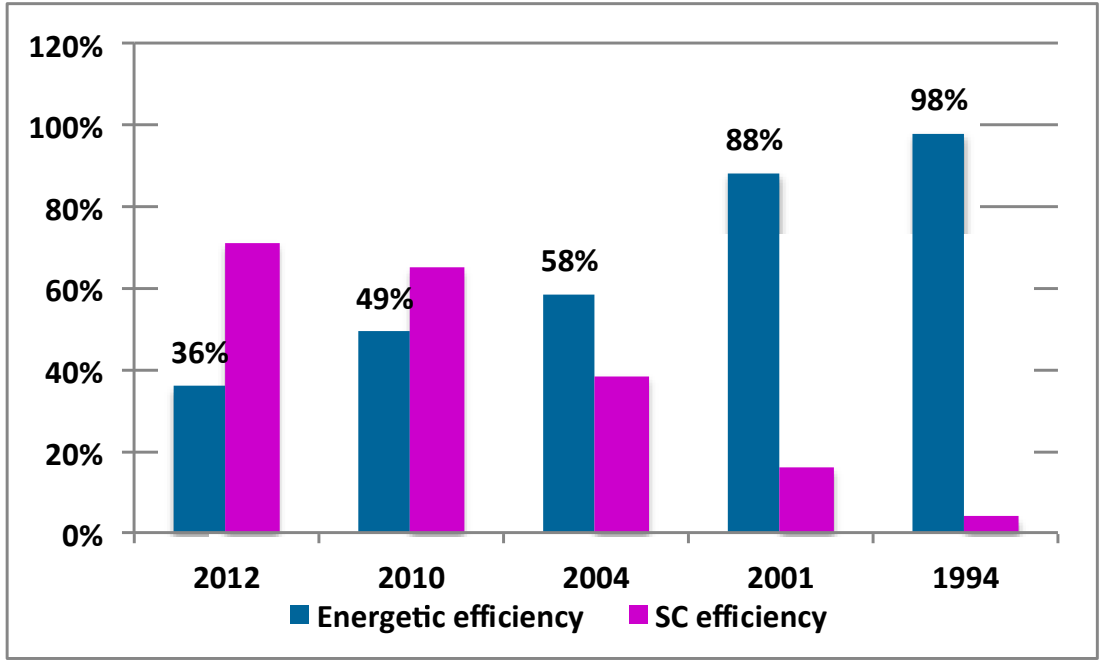

Figure 5: Energy exploitability (RMSW vs MSW) and SC efficiency. 
expected net electricity generation from incineration as $25 \%$, the electricity generable from RMSW should be around 91,300,000 $\mathrm{kWh}_{\mathrm{e}} /$ year (about 5 times higher than the one expected from the digesters). Data related to the year 2012 do not confirm this forecast as both the amount of RMSW and its LHV are lower. This instability was one of the topics in the local discussion about the availability of this option. If there is not a guaranteed input for a waste-to-energy plant, the tariff to be applied "at the gate" becomes unstable. This is one of the reasons why the local strategy moved towards SRF.

The 2012 RMSW characteristics (high LHV, low food waste content, overall amount significantly lower (about 70,000 t/y), expected low $\mathrm{Hg}$ and $\mathrm{Cl}$ content $[17,20,22])$ recently opened a local discussion on the viability of a direct classification of RMSW as SRF to be sent "directly" into existing plants also out of the provincial territory. This is a demonstration of how an extreme SC can affect the Waste-to-Energy strategies in the MSW sector.

\section{Conclusions}

SC can cause significant indirect modifications of RMSW that can become similar to a SRF, opening to near direct co-combustion opportunities in existing industrial plants (cement factories, thermal power plants, etc.). This pathway could decrease the cost of solutions alternative to direct combustion in dedicated plants (incinerators).

In spite of its high LHV, the energy exploitable, compared to MSW, is significantly reduced as a consequence of SC. That decreases the incineration scale to a value that must be well analyzed in terms of economic viability. Indeed incineration is affected by a significant scale effect that is more relevant to low plant capacity. The parallel increase of food waste SC opens to interesting energy recovery by anaerobic digestion. Of course the viability of this strategy needs a steady cooperation of the citizens that must guarantee an efficient separation of food waste. Data presented for the selected case-study demonstrate that when an organization effort is well performed, the acceleration of SC is remarkable, with significant consequences on the overall strategy of MSW management.

From the above-presented scenarios, it is clear that the MSW management evolved to a waste-to-energy configuration (thanks to the direct and indirect generation of biogas and SRF-like) integrated with mass valorization (thanks to the SC optimization).

An open question concerns the quality of the source separated waste streams. The improvement of their quality is one of the main targets of the future MSW management in the analyzed province. The first tool adopted to this concern can be considered the introduction of the punctual tariff (each user pays according to the RMSW that generates). This topic will be the subject of a future article. 


\section{Acknowledgements}

The author wishes to acknowledge PAT (Provincia Autonoma di Trento Autonomous Province of Trento, Italy) and Mr. Zatelli, in particular, for the support in data availability.

\section{References}

[1] McCollough, J., Determinants of a throwaway society - A sustainable consumption issue. Journal of Socio-Economics, 41(1), pp. 110-117, 2012.

[2] Rada, E.C., Effect of MSW selective collection on waste-to-energy strategies. WIT Transaction on Ecology and the Environment, 176, pp. 215-223, 2013.

[3] Consonni, S., Giuliano, M., MAssarutto, A., Ragazzi, M. \& Saccani, C., Material and energy recovery in integrated waste management systems: Project overview and main results. Waste Management, 31(9-10), 2057-2065, 2011.

[4] http://appsso.eurostat.ec.europa.eu

[5] CAC - Cooperativa Atlantide di Cervia, Progetto scuola città, Rifiuti: Energia del futuro, 1998, www.atlantide.net

[6] Gotaas, H.B., Composting; sanitary disposal and reclamation of organic wastes. Monograph series. World Health Organization, 31, pp. 1-205, 1956.

[7] Johnson, G.E., Kunka, L.M., Decker, W.A. \& Forney, A.J., Production of methane by the anaerobic decomposition of garbage and waste materials. American Chemical Society, Division of Fuel Chemistry, 16(4), pp. 70-78, 1972.

[8] Dennis, R., Muller, F.L., Kristal, E. \& Silverman, L., Special incineration studies - institutional design. ORINS Reports. U.S. Atomic Energy Commission 7593, pp. 344-364, 1960.

[9] Adani, F., Scatigna, L. \& Genevini, P., Biostabilization of mechanically separated municipal solid waste fraction. Waste Management and Research, 18(5), pp. 471-477, 2000.

[10] Rada, E.C., Ragazzi, M., Panaitescu, V. \& Apostol, T., Experimental characterization of municipal solid waste bio-drying. WIT Transactions on Ecology and the Environment, 92, pp. 295-302, 2006.

[11] Cadena, E., Colon, J., Artola, A., Sanchez, A. \& Font, X., Environmental impact of two aerobic composting technologies using life cycle assessment. International Journal of Life Cycle Assessment, 14(5), 401-410, 2009.

[12] Rada, E.C. \& Ragazzi, M., Critical analysis of PCDD/F emissions from anaerobic digestion. Water Science and Technology, 58(9), pp. 1721-1725, 2008.

[13] Rada, E.C., Ragazzi, M., Zardi, D., Laiti, L. \& Ferrari, A., PCDD/F environmental impact from municipal solid waste bio-drying plant. Chemosphere, 84(3), pp. 289-295, 2011.

[14] Ragazzi, M. \& Rada, E.C., Multi-step approach for local environmental impact comparison among conventional and innovative MSW thermochemical treatments. Chemosphere, 89(6), pp. 694-701, 2012. 
[15] Torretta, V., Ragazzi, M., Istrate, I. \& Rada, E.C., Management of waste electronic and electronic equipment's in two EU countries: a comparison. Waste Management, 33(1), pp. 117-122, 2013.

[16] Da Cruz, N.F., Simões, P. \& Marques, R.C., Economic cost recovery in the recycling of packaging waste: The case of Portugal. Journal of Cleaner Production, 37, pp. 8-18, 2012.

[17] Rada, E.C., Ragazzi, M. \& Fedrizzi, P., WEB-GIS oriented system viability for municipal solid waste collection optimization in developed and transient economies. Waste Management, 33(4), pp. 785-792, 2013.

[18] Ionescu, G., Rada, E.C., Ragazzi, M., Marculescu, C., Badea, A. \& Apostol T., Integrated municipal solid waste scenario model using advanced pretreatment and waste to energy processes. Energy Conversion and Management, 76, pp. 1083-1092, 2013.

[19] Rada, E.C. \& Ragazzi, M., Selective collection as a pretreatment for indirect solid recovered fuel generation. Waste Management, 34(2), pp. 291-297, 2014.

[20] Colon, J., Mestre-Montserrat, M., Puig-Ventosa, I. \& Sanchez, A., Performance of compostable baby used diapers in the composting process with the organic fraction of municipal solid waste. Waste Management, 33(5), pp. 1097-1103, 2013.

[21] http://www.adep.provincia.tn.it

[22] Rada, E.C. \& Andreottola, G., RDF/SRF: which perspectives for its future in the EU. Waste Management, 32(6), pp. 1059-1060, 2012.

[23] Ragazzi, M. \& Rada, E.C., RDF/SRF evolution and MSW bio-drying. WIT Transaction on Ecology and the Environment, 163, pp. 199-208, 2012.

[24] Velis, C.A. \& Cooper, J., Are solid recovered fuels resource-efficient? Waste Management and Research, 31(2), pp. 113-114, 2013.

[25] Velis, C., Wagland, S., Longhurst, P., Pollard, S., Robson, B., Sinfield, K. $\&$ Wise, S., Solid recovered fuel: Influence of waste stream composition and processing on chlorine content and fuel quality. Environmental Science and Technology, 46(3), pp. 1923-1931, 2012. 